\title{
Effects of Geometrical Difference of Unsaturated Aliphatic Polyesters on Their Biodegradability II. Isomerization of Poly(maleic anhydride-co-propylene oxide) in the Presence of Morpholine
}

\author{
Shigenobu TAKENOUCHI, Akinori TAKASU, Yoshihito INAI, \\ and Tadamichi HIRABAYASHI ${ }^{\dagger}$ \\ Department of Environmental Technology and Urban Planning, Graduate School of Engineering, \\ Nagoya Institute of Technology, Gokiso-cho, Showa-ku, Nagoya 466-8555, Japan
}

(Received September 12, 2001; Accepted November 9, 2001)

\begin{abstract}
Ring-opening copolymerizations of succinic anhydride (SAn, 1) or maleic anhydride (MAn, 2) with propylene oxide (PO) were carried out by using magnesium diethoxide $\left(\mathrm{Mg}(\mathrm{OEt})_{2}\right)$ as a catalyst. The unsaturated polyester (P2a) was found to have only $Z$-configuration around a $\mathrm{C}=\mathrm{C}$ double bond from its ${ }^{1} \mathrm{H}$ and ${ }^{13} \mathrm{C}$ NMR spectra. Isomerization reaction of $\mathbf{P 2 a}$ from $Z$ - to $E$-configuration was performed in 1,2-dichloroethane with a catalytic amount of morpholine. Thus unsaturated polyesters, P2b-e, having the same molecular weight but the different ratio of $Z$-/E-configuration could be optionally prepared from one original polymer P2a by controlling isomerization reaction time. Biodegradability of these polyester samples was evaluated from their biochemical oxygen demand (BOD) values in the presence of an activated sludge. Polyester P2a was hardly degraded during measurement. However, polyesters P2b-e, partially containing $E$-configuration of the $\mathrm{C}=\mathrm{C}$ double bond, degraded considerably faster than P2a itself. The biodegradability of saturated polyester $\mathbf{P 1}$ was also examined to compare with the $\mathbf{P 2}$-series.

KEY WORDS Biodegradability / Unsaturated Polyester / Geometrical Isomer / Ring-Opening Copolymerization / Cyclic Acid Anhydride / Propylene Oxide /
\end{abstract}

Synthetic polymeric materials have provided many advantages in our daily life for the last century, and become one of the most important materials. When once almost all of synthetic polymers are disposed after use, however, those cause serious environmental problems. Thus, biodegradable polymers have received much attention in recent years as one of the answer to solve the problems. In fact, biodegradable polymers, especially aliphatic polyesters, have been widely investigated by many scientists in the world.

In spite of a large number of studies on biodegradability of polyesters, little attention has been given to unsaturated polyesters. ${ }^{1-6}$ Tokiwa and Suzuki reported that a few unsaturated polyesters containing 2-butenediol unit could be hydrolyzed by lipase. ${ }^{1}$ On the other hand, slightly cross-linked unsaturated polyesters, poly(hexamethylene fumarate) and poly(cis-2-butene fumarate), were hardly hydrolyzed by lipase.

A carbon-carbon double bond in unsaturated polyesters has two geometrical isomers ( $Z$ - and $E$ configuration), and such difference should affect their biodegradability. In controlling the biodegradation rate of polyester, it is very helpful to make geometrical effects clear. In our previous paper, ${ }^{6}$ it was shown that in comparison with saturated polyesters, the ef-

${ }^{\dagger}$ To whom correspondence should be addressed. ficient degradation was prevented by introducing $Z$ configuration of $\mathrm{C}=\mathrm{C}$ double bond in the unsaturated polyesters but introducing $E$-configuration did not affect so remarkably. However, the variety of samples was limited because of the difficulty in preparation of samples having the same molecular weight and the different $Z / E$ ratio. Although polycondensation method of unsaturated acid anhydrides with diol in the presence of acid as a catalyst was employed in previous work, the $\mathrm{C}=\mathrm{C}$ double bond of $Z$-configuration took place isomerization into $E$-configuration as a side reaction during polycondensation. ${ }^{7-10}$ This is a reason not to obtain $100 \% Z$-configuration isomer. Moreover longer polymerization time so as to achieve polymers with high molecular weight resulted in higher contents of $E$-configuration.

In this paper, we employ ring-opening polymerization between acid anhydrides and epoxydes with a catalyst but not protonic catalyst. ${ }^{5,11-13}$ Thus polyesters P1 and P2a could be obtained from succinic anhydride (SAn, 1) or maleic anhydride (MAn, 2) with propylene oxide (PO), respectively. In accordance with our expectation, the resulting polyester P2a was confirmed as the polymer with $100 \% Z$-configuration. Furthermore unsaturated polyesters have various $Z / E$ ratios could be readily prepared through isomerization of one original polymer P2a in 1,2-dichloroethane (DCE) in the pres- 

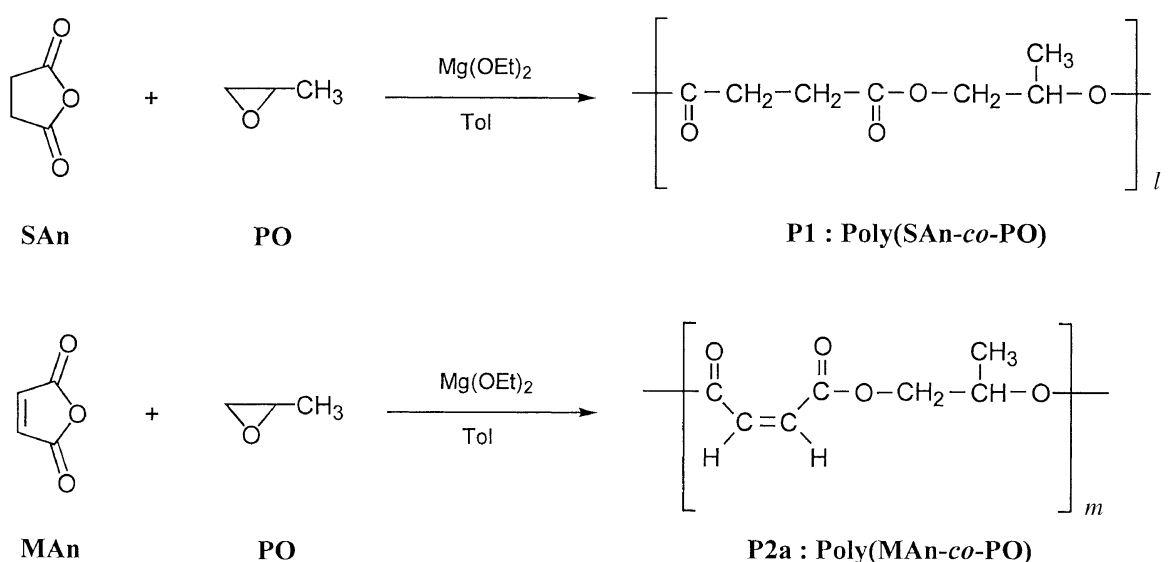

Scheme 1. Ring-opening copolymerization of SAn or MAn with PO.

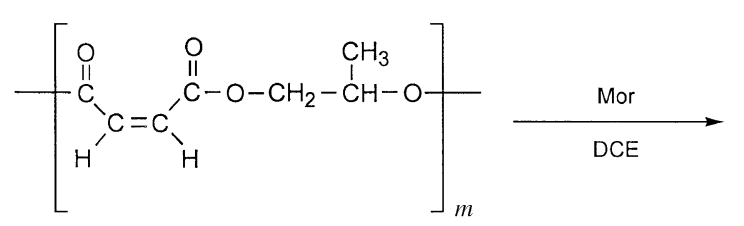

Polyester P2a

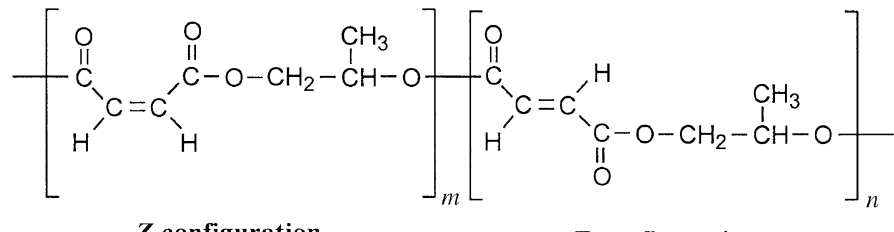

E-configuration

Polyester P2b-e

Scheme 2. Isomerization of poly(MAn-co-PO) (P2a) catalyzed by Mor.

ence of morpholine (Mor) as a catalyst. ${ }^{14}$ Molecular weight of the polyesters obtained by this process were nearly same with the original polymer sample (P2a). By using these samples having same molecular weight, geometrical effects on the biodegradability of unsaturated polyesters were studied in details.

\section{EXPERIMENTAL}

\section{Materials}

Succinic anhydride (SAn), and maleic anhydride (MAn) were purchased from Nacalai Tesque, Inc. These anhydrides were purified by recrystallization from chloroform $\left(\mathrm{CHCl}_{3}\right)$. Propylene oxide (PO) and magnesium ethoxide $\left(\mathrm{Mg}(\mathrm{OEt})_{2}\right)$ were available from Wako Pure Chemical Industries, Ltd. Morpholine (Mor) was also purchased from Nacalai Tesque, Inc. $\mathrm{PO}, \mathrm{Mor}$, Toluene (Tol), $\mathrm{CHCl}_{3}$, and 1,2dichloroethane (DCE) were purified by distillation before use.

\section{Measurement}

FT-IR spectra were recorded for film samples cast on $\mathrm{KBr}$ disk from chloroform solutions, using a JASCO FT/IR-430 spectrometer. ${ }^{1} \mathrm{H}$ and ${ }^{13} \mathrm{C}$ NMR were measured in $\mathrm{CDCl}_{3}$ at $27^{\circ} \mathrm{C}$ by using a Bruker DPX$200 \mathrm{MHz}$ spectrometer. The chemical shifts were expressed as $\delta$ value apart from tetramethylsilane (TMS). The number-average molecular weight $\left(M_{\mathrm{n}}\right)$ and poly- dispersity index $\left(M_{\mathrm{w}} / M_{\mathrm{n}}\right)$ of polymers were determined by gel permeation chromatography (GPC) method, calibrated with polystyrene standards. A GPC system of Tosoh HLC-8020 equipped with a Tosoh RI-8020 detector and Tosoh G2000-HXL, G3000-HXL, G4000$\mathrm{HXL}$, and G5000-HXL columns was run at $40^{\circ} \mathrm{C}$. Tetrahydrofuran was used as an eluent. Glass transition temperature $\left(T_{\mathrm{g}}\right)$ of the samples were determined by differential scanning calorimetry (DSC) using a Seiko Instrument DSC $220 \mathrm{C}$ in a range from -100 to $120^{\circ} \mathrm{C}$ at a heating rate of $10^{\circ} \mathrm{C} \mathrm{min}^{-1}$.

Synthesis of Poly(succinic anhydride-co-propylene oxide) (P1)

A mixture of $0.83 \mathrm{~g}(14.3 \mathrm{mmol})$ of $\mathrm{PO}$ and $1.40 \mathrm{~g}$ $(14.3 \mathrm{mmol})$ of SAn was dissolved in $2.0 \mathrm{~mL}$ of Tol in a glass tube at room temperature under the nitrogen atmosphere. This mixture was then polymerized by adding $0.013 \mathrm{~g}(0.11 \mathrm{mmol})$ of $\mathrm{Mg}(\mathrm{OEt})_{2}$. After stirring at $100^{\circ} \mathrm{C}$ for $48 \mathrm{~h}$, the mixture was diluted with $\mathrm{CHCl}_{3}$ and then washed with water containing a trace amount of $\mathrm{HCl}$ to remove inorganic components completely. The organic solution was poured into diethyl ether, and the supernatant was removed by decantation. After reprecipitation from $\mathrm{CHCl}_{3}$ solution into diethyl ether (as a non-solvent), the polymeric materials were collected and dried in vacuo to give polyester $\mathbf{P 1}$ [Yield; $0.88 \mathrm{~g}, 39.1 \%$, (P1 in Table I)]. IR ( $\mathrm{KBr}$ disk, $\left.\mathrm{cm}^{-1}\right)$ : $2984\left[v_{\mathrm{C}-\mathrm{H}}\right], 1736$ 
Table I. Ring-opening copolymerization of SAn or MAn with PO using $\mathrm{Mg}(\mathrm{OEt})_{2}$

\begin{tabular}{|c|c|c|c|c|c|c|c|c|c|c|c|}
\hline Polyester & $\frac{\text { Mon }}{\mathrm{mn}}$ & $\frac{\mathrm{mer}}{\mathrm{ol}}$ & $\frac{\mathrm{Mg}(\mathrm{OE})_{2}}{\mathrm{mmol}}$ & $\frac{\text { Toluene }}{\mathrm{mL}}$ & $\frac{\text { Temp }}{{ }^{\circ} \mathrm{C}}$ & $\frac{\text { Time }}{\mathrm{h}}$ & $\frac{\text { Yield }}{\mathrm{g}(\%)}$ & $\begin{array}{c}M_{\mathrm{n}}^{\mathrm{a}} \\
\times 10^{-3}\end{array}$ & $M_{\mathrm{w}} / M_{\mathrm{n}}^{\mathrm{a}}$ & $m_{1} / m_{2}{ }^{\mathrm{b}}$ & $Z / E^{\mathrm{c}}$ \\
\hline P1 & SAn (14.3) & $\mathrm{PO}(14.3)$ & 0.114 & 2.0 & 100 & 48 & $0.88(39.1)$ & 5.0 & 1.34 & $50 / 50$ & - \\
\hline P2a & $\operatorname{MAn}(142.8)$ & PO (142.8) & 1.170 & 20.0 & 80 & 48 & $9.43(42.2)$ & 4.2 & 1.17 & $49 / 51$ & $100 / 0$ \\
\hline
\end{tabular}

${ }^{\text {a } D e t e m i n e d ~ b y ~ G P C ~ c a l c u l a t e d ~ b y ~ p o l y s t y r e n e ~ s t a n d a r d s ; ~ e l u e n t, ~ T H F . ~}{ }^{b}$ Molar ratio of MAn or SAn $\left(m_{1}\right)$ unit to PO $\left(m_{2}\right)$ unit in polymer, determined by ${ }^{1} \mathrm{H}$ NMR. ${ }^{\mathrm{c}}$ Molar ratio of $Z$ - and $E$-conformation unit in polymer, determined by ${ }^{1} \mathrm{H}$ NMR.

Table II. Z- to E-configuration isomerization reaction of poly(MAn-co-PO) (P2a) in DCE in the presence of Mor ${ }^{\mathrm{a}}$

\begin{tabular}{|c|c|c|c|c|c|c|}
\hline Polymer & $\frac{\text { Reaction Time }}{\min }$ & $\frac{\text { Yield }}{\mathrm{g}(\%)}$ & $\boldsymbol{Z} / \boldsymbol{E}^{\mathrm{b}}$ & $\begin{array}{c}M_{\mathrm{n}}^{\mathrm{c}} \\
\times 10^{-3} \\
\end{array}$ & $M_{\mathrm{w}} / M_{\mathrm{n}}^{\mathrm{c}}$ & $\frac{T_{\mathrm{g}}^{\mathrm{d}}}{{ }^{\circ} \mathrm{C}}$ \\
\hline P2a & - & - & $100 / 0$ & 4.2 & 1.17 & -14.4 \\
\hline $\mathbf{P} 2 \mathbf{b}$ & 10 & $0.644(82.6)$ & $66 / 34$ & 4.5 & 1.17 & -7.0 \\
\hline P2c & 30 & $0.637(81.7)$ & $37 / 63$ & 4.8 & 1.15 & -0.6 \\
\hline P2d & 60 & $0.616(79.0)$ & $16 / 84$ & 4.9 & 1.15 & 1.7 \\
\hline P2e & 120 & $0.622(79.7)$ & $8 / 92$ & 5.0 & 1.15 & 4.0 \\
\hline
\end{tabular}

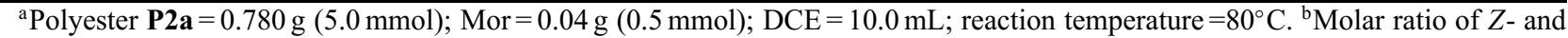
$E$-conformation unit in polymer, determined by ${ }^{1} \mathrm{H}$ NMR. ${ }^{\mathrm{c}}$ Determined by GPC calculated by polystyrene standards; eluent, THF. ${ }^{\mathrm{d}}$ Determined by DSC; heating rate, $10^{\circ} \mathrm{C} \mathrm{min}^{-1}$.

$\left[v_{\mathrm{C}=\mathrm{O}}(\right.$ ester $\left.)\right]$, and $1156\left[v_{\mathrm{C}-\mathrm{O}-\mathrm{C}}(\right.$ ester $\left.)\right] .{ }^{1} \mathrm{H}$ NMR $\left(\mathrm{CDCl}_{3}, \delta \mathrm{ppm}\right): 5.30-5.02\left[\mathrm{OCH}_{2} \mathrm{CH}\left(\mathrm{CH}_{3}\right) \mathrm{O}\right], 4.29$ $3.98\left[\mathrm{OCH}_{2} \mathrm{CH}\left(\mathrm{CH}_{3}\right) \mathrm{O}\right], 2.65-2.62\left[\mathrm{OCH}_{2} \mathrm{CH}_{2} \mathrm{O}\right]$, and 1.31-1.27 [ $\left.\mathrm{OCH}_{2} \mathrm{CH}\left(\mathrm{CH}_{3}\right) \mathrm{O}\right] .{ }^{13} \mathrm{C} \mathrm{NMR}\left(\mathrm{CDCl}_{3}\right.$, $\delta$ ppm): $172.4[\mathrm{CO}], 68.9\left[\mathrm{OCH}_{2} \mathrm{CH}\left(\mathrm{CH}_{3}\right) \mathrm{O}\right], 66.6$ $\left[\mathrm{OCH}_{2} \mathrm{CH}\left(\mathrm{CH}_{3}\right) \mathrm{O}\right], 29.5\left[\mathrm{OCCH}_{2} \mathrm{CH}_{2} \mathrm{CO}\right]$, and 16.8 $\left[\mathrm{OCH}_{2} \mathrm{CH}\left(\mathrm{CH}_{3}\right) \mathrm{O}\right]$.

Synthesis of Poly(maleic anhydride-co-propylene oxide) (P2a)

Polyester P2a was prepared by a similar manner to that of polyester $\mathbf{P 1}$, except for the reaction temperature $\left(80^{\circ} \mathrm{C}\right)$ [Yield; $9.43 \mathrm{~g}, 42.2 \%$ (P2a in Table I)]. IR $\left(\mathrm{KBr}\right.$ disk, $\left.\mathrm{cm}^{-1}\right)$ : $2987\left[v_{\mathrm{C}-\mathrm{H}}\right], 1735\left[v_{\mathrm{C}=\mathrm{O}}\right.$ (ester)], and $1161\left[v_{\mathrm{C}-\mathrm{O}-\mathrm{C}}(\right.$ ester $\left.)\right] .{ }^{1} \mathrm{H}$ NMR $\left(\mathrm{CDCl}_{3}, \delta \mathrm{ppm}\right)$ : 6.29-6.20 $[\mathrm{CH}=\mathrm{C} H(Z$-configuration $)], \quad 5.35-5.16$ $\left[\mathrm{OCH}_{2} \mathrm{CH}\left(\mathrm{CH}_{3}\right) \mathrm{O}\right], 4.31-4.23 \quad\left[\mathrm{OCH}_{2} \mathrm{CH}\left(\mathrm{CH}_{3}\right) \mathrm{O}\right]$, and 1.34-1.30 $\left[\mathrm{OCH}_{2} \mathrm{CH}\left(\mathrm{CH}_{3}\right) \mathrm{O}\right] .{ }^{13} \mathrm{C} \mathrm{NMR}\left(\mathrm{CDCl}_{3}\right.$, $\delta$ ppm): $164.7[C \mathrm{O}], \quad 130.5-129.3 \quad[\mathrm{CH}=\mathrm{CH} \quad(Z-$ configuration)], $\quad 69.2 \quad\left[\mathrm{OCH}_{2} \mathrm{CH}\left(\mathrm{CH}_{3}\right) \mathrm{O}\right], \quad 66.4$ $\left[\mathrm{OCH}_{2} \mathrm{CH}\left(\mathrm{CH}_{3}\right) \mathrm{O}\right]$, and $16.2\left[\mathrm{OCH}_{2} \mathrm{CH}\left(\mathrm{CH}_{3}\right) \mathrm{O}\right]$.

\section{Isomerization Reaction of Polyester (P2a)}

A typical experimental procedure is as follows. Polyester P2a $(0.78 \mathrm{~g}, 5.0 \mathrm{mmol})$ was placed into a $50 \mathrm{~mL}$ round-bottomed flask equipped with reflux condenser, dissolved completely in $10.0 \mathrm{~mL}$ of DCE at room temperature under the nitrogen atmosphere. After Mor $(0.04 \mathrm{~g}, 0.5 \mathrm{mmol})$ had been added, the flask was immediately immersed in an oil bath and heated up to $80^{\circ} \mathrm{C}$. The mixture was stirred by magnetic stirrer at $80^{\circ} \mathrm{C}$ for $10-120$ minutes. After cooling down to room temperature, the mixture was diluted with $\mathrm{CHCl}_{3}$, and then the organic layer was poured into diethyl ether to obtain precipitate. The precipitate was collected and dried in vacuo at room temperature to give polyester P2b-e [Yield; $0.644 \mathrm{~g}, 82.6 \%$, for polyester $\mathbf{P 2 b}$, the others are in Table II]. IR ( $\mathrm{KBr}$ disk, $\left.\mathrm{cm}^{-1}\right): 2986\left[v_{\mathrm{C}-\mathrm{H}}\right], 1726\left[v_{\mathrm{C}=\mathrm{O}}(\right.$ ester $\left.)\right]$, and 1158 $\left[v_{\mathrm{C}-\mathrm{O}-\mathrm{C}}(\mathrm{ester})\right] .{ }^{1} \mathrm{H}$ NMR $\left(\mathrm{CDCl}_{3}, \delta \mathrm{ppm}\right): 6.91-6.81$ [CH=CH(E-configuration)], 6.30-6.20 [CH=CH(Zconfiguration) $], \quad 5.37-5.16 \quad\left[\mathrm{OCH}_{2} \mathrm{CH}\left(\mathrm{CH}_{3}\right) \mathrm{O}\right]$, 4.38-4.14 [OCH $\left.\mathrm{OH}_{2} \mathrm{CH}\left(\mathrm{CH}_{3}\right) \mathrm{O}\right]$, and 1.36-1.31 $\left[\mathrm{OCH}_{2} \mathrm{CH}\left(\mathrm{CH}_{3}\right) \mathrm{O}\right] .{ }^{13} \mathrm{C}$ NMR $\left(\mathrm{CDCl}_{3}, \delta \mathrm{ppm}\right)$ : 165.0 [CO], 134.0-133.7 [ $\mathrm{CH}=\mathrm{CH}(E$-configuration $)]$, 130.9-129.7 $[\mathrm{CH}=\mathrm{CH} \quad$ (Z-configuration) $], \quad 69.5$ $\left[\mathrm{OCH}_{2} \mathrm{CH}\left(\mathrm{CH}_{3}\right) \mathrm{O}\right], 66.8\left[\mathrm{OCH}_{2} \mathrm{CH}\left(\mathrm{CH}_{3}\right) \mathrm{O}\right]$, and 16.8 $\left[\mathrm{OCH}_{2} \mathrm{CH}\left(\mathrm{CH}_{3}\right) \mathrm{O}\right]$.

\section{Biochemical Oxygen Demand (BOD) Test}

Biochemical oxygen demand (BOD) value of the samples was determined by the oxygen consumption method according to the JIS $\mathrm{K} 6950$ at $25^{\circ} \mathrm{C}$, using a BOD tester (Model 200F, TAITEC Co., Koshigaya, Japan). The activated sludge was available from Municipal disposal plant in Nagoya. The incubation medium was composed of $\mathrm{K}_{2} \mathrm{HPO}_{4}$ (217.5), $\mathrm{KH}_{2} \mathrm{PO}_{4}$ (85.0), $\mathrm{Na}_{2} \mathrm{HPO}_{4} \cdot 2 \mathrm{H}_{2} \mathrm{O}$ (334.0), $\mathrm{NH}_{4} \mathrm{Cl}$ (5.0), $\mathrm{CaCl}_{2} \cdot 2 \mathrm{H}_{2} \mathrm{O}(36.4), \mathrm{MgSO}_{4} \cdot 7 \mathrm{H}_{2} \mathrm{O}(22.5), \mathrm{FeCl}_{3} \cdot 6 \mathrm{H}_{2} \mathrm{O}$ $\left(0.25 \mathrm{mg} \mathrm{L}^{-1}\right)$, kept at $\mathrm{pH}=7.4 \pm 0.1$. Since polyester P1, and P2a-e were viscous liquid, each sample in chloroform solution was cast to film on bottom of the bottle in height of $2 \mathrm{~cm}$. The concentration of polymers in the incubation medium was $100 \mathrm{mg} \mathrm{L}^{-1}$. 


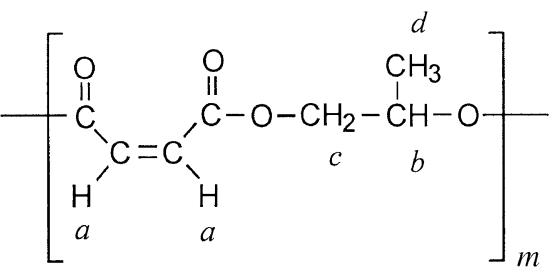

(a)
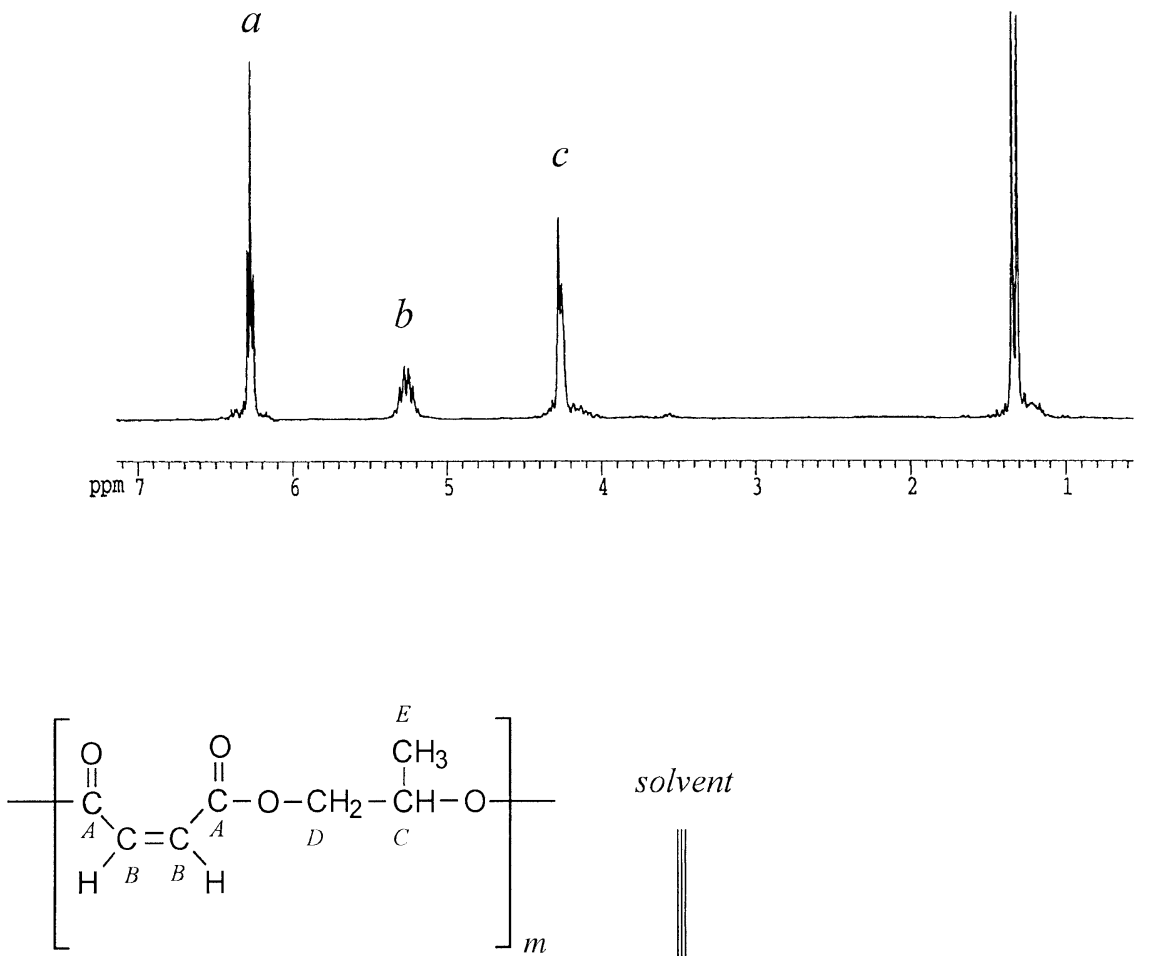

solvent

(b)

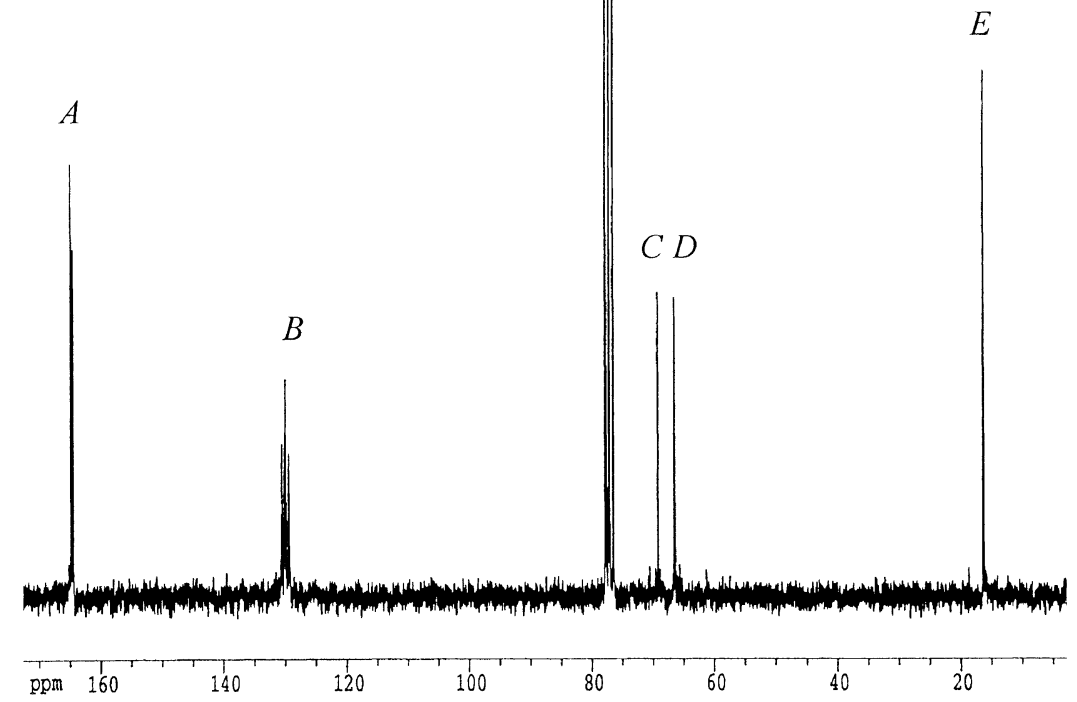

Figure 1. NMR spectra of poly(MAn-co-PO) (P2a, in Table I) in $\mathrm{CDCl}_{3}$ at $27^{\circ} \mathrm{C}$; (a) ${ }^{1} \mathrm{H} \mathrm{NMR}$, (b) ${ }^{13} \mathrm{C}$ NMR.

\section{RESULTS AND DISCUSSION}

Ring-Opening Copolymerization of Acid Anhydrides and Propylene Oxide

In our previous study, poly(maleic anhydride-coethylene glycol) were synthesized by solution polycon- densation method. ${ }^{6} Z$-conformation rich unsaturated polyester (molar ratio $Z / E=81 / 19$ ) could be prepared, but $100 \% Z$-conformation was never obtained because of the $\mathrm{C}=\mathrm{C}$ double bond of $Z$-configuration isomerized into $E$-configuration as a side reaction during polycondensation. To clarify geometric structure effects on their biodegradability, ring-opening copolymerization 


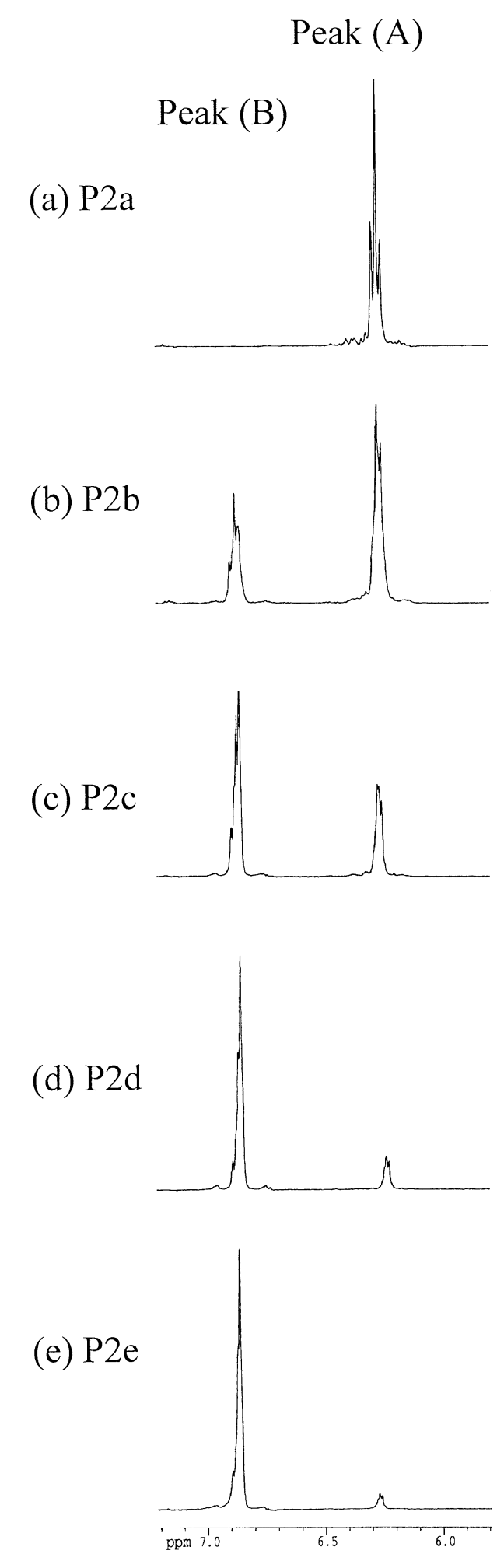

Figure 2. ${ }^{1} \mathrm{H}$ NMR spectra along reaction time for the isomerization of polymer P2a.

of SAn or MAn with PO were examined according to Scheme $1 .^{5,11-13}$ The results are summarized in Table I.

In the synthesis of polyester P1 and P2a, lightbrown viscous samples having no $T_{\mathrm{m}}$ could be obtained. The NMR spectra for polyester P2a are shown in Figure 1. Although small peaks around $6.3,4.1$, and $1.2 \mathrm{ppm}$ could be assigned to terminal $-\mathrm{COC} H=\mathrm{CHCOOH}$ (Z-configuration), $-\mathrm{OCH}_{2} \mathrm{CH}\left(\mathrm{CH}_{3}\right) \mathrm{OH}$, and $-\mathrm{OCH}_{2} \mathrm{CH}\left(\mathrm{CH}_{3}\right) \mathrm{OH}$ respectively, very few peaks around $3.6 \mathrm{ppm}$ assignable to homosequence of PO could be observed in the NMR spectra. The molar ratios of SAn or MAn unit to PO unit in the polymers, $m_{1} / m_{2}$, were almost $50 / 50$ within experimental error. The geometrical structure of $\mathrm{C}=\mathrm{C}$ double bonds in polyester P2a was confirmed as only $Z$-configuration by ${ }^{1} \mathrm{H}$ and ${ }^{13} \mathrm{C}$ NMR analyses.

The polymer P1 and P2a obtained by ring-opening copolymerization method were essentially linear polymers soluble in $\mathrm{CHCl}_{3}$ completely, but molecular weight $\left(M_{\mathrm{n}}\right)$ over $10^{4}$ could not be achieved as well as solution polycondensation method described in our previous work. ${ }^{6}$ In the case of saturated polyesters, chain extension reaction is often employed to make up polyester having high molecular weight. ${ }^{15,16}$ In order to obtain high molecular weight of unsaturated polyester samples, chain extension reaction of polymer P2a was also examined by using a Titanium(IV) isopropoxide as a catalyst at $80^{\circ} \mathrm{C}$. However it resulted in gelation of the polymer in parallel with the chain extension reaction. In our experimental knowledge, the unsaturated polyesters were tended to face with cross-linking when their molecular weight became over about 5000 . Therefore it seems that preparation of linear unsaturated polyesters having high molecular weight is difficult.

Taking a few reports into consideration, strange behavior of a few samples for biodegradation test in the previous works might be subject to effects of crosslinking even if it occurred slightly. ${ }^{1,3}$ To estimate distinct geometrical effects in biodegradation test, the sample should be required to avoid cross-linking and, as a result, have rather moderate degree of polymerization. The present samples are suitable for the above requirement.

\section{Isomerization of Polymer P2a Catalyzed by Mor}

It is one of the final goal for us to design various types of chemical system for controlling the biodegradation rate of polymers. For this purpose, our attention has been focused upon how much degree the different $Z / E$ ratios of $\mathrm{C}=\mathrm{C}$ double bonds in the unsaturated aliphatic polyesters affect their biodegradability. Therefore it is worth while preparing some unsaturated polyesters having a wide variety of the $Z / E$ ratio.

One reasonable route could be established in this work. It is well known the $\mathrm{C}=\mathrm{C}$ double bond in $Z$ configuration can be isomerized into $E$-configuration in the presence of some amine compounds as a catalyst. ${ }^{14}$ Thus isomerization of polyester P2a having all $Z$ configuration of $\mathrm{C}=\mathrm{C}$ double bonds was examined with 

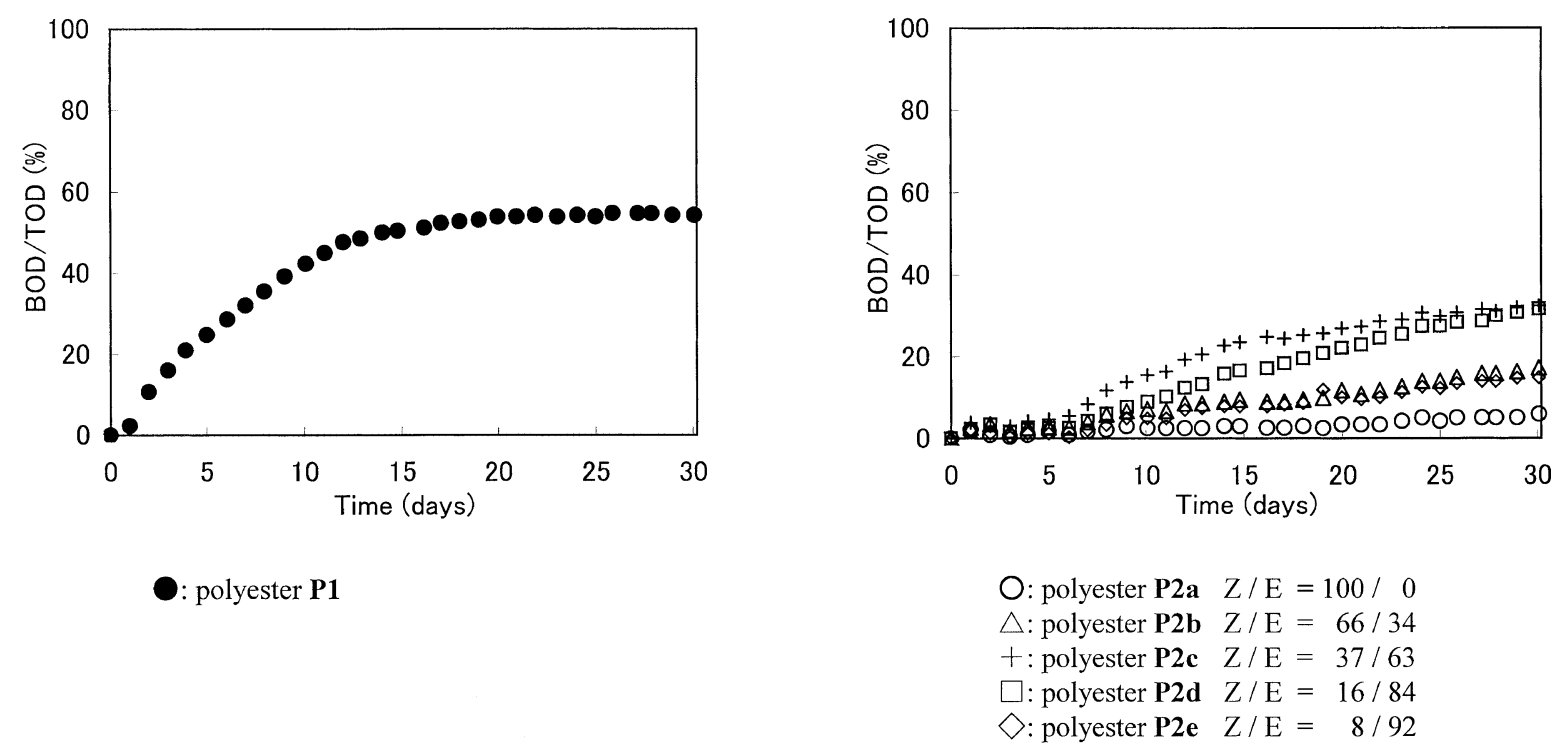

Figure 3. Biodegradability of saturated polyester P1 and unsaturated polyester P2a-e evaluated by biochemical oxygen demand (BOD).

Mor. The results are summarized in Table II, showing that an optional $Z / E$ ratio in the unsaturated polyesters can be achieved without any serious troubles.

Figure 2 represents ${ }^{1} \mathrm{H}$ NMR spectra of a series of polyester P2a-e derived through isomerization of polymer P2a. The occurrence of isomerization from $Z$ - to $E$-configuration was clearly confirmed by the appearance of peak (B) at about $6.8 \mathrm{ppm}$ which could be assigned to olefinic methine proton of $E$-configuration. As reaction time was prolonged longer, the intensity of peak (B) became stronger. Instead, the intensity of peak (A) at about $6.2 \mathrm{ppm}$ assignable to methine protons of $Z$-configuration was decreased gradually. The molar fraction ratios of $Z$ - $/ E$-configuration of $-\mathrm{C}=\mathrm{C}-$ moiety in the samples could be calculated from the intensity ratios of peak (A)/peak (B). These numerical data are summarized in Table II. Thus unsaturated polyesters, P2b-e, having the same molecular weight but the different ratio of $Z$-/E-configuration could be optionally prepared from one original polymer P2a by controlling isomerization reaction time. The variety of $Z / E$ values was wide enough to investigate geometrical effects on biodegradability.

The molar ratio of maleic and fumaric acid unit to $\mathrm{PO}$ unit in polyester P2a-e $\left[m_{1} / m_{2}=\left(m_{\mathrm{MAn}}+m_{\mathrm{FA}}\right) / m_{\mathrm{PO}}\right]$ was, of course, kept as 50/50. Furthermore, each molecular weight $\left(M_{\mathrm{n}}\right)$ of polyesters containing the original P2a was found to be similar irrespective of the different $Z / E$ value. This is a very important advantage because there is no need to discuss the effects of molecular weight of the samples on their biodegradability.

Glass transition temperature $\left(T_{\mathrm{g}}\right)$ of the above polyesters was determined by DSC. As the fraction of $E$-configuration went on increasing, $T_{\mathrm{g}}$ raised up grad- ually. Therefore it is presumed that increase of the fraction of $E$-configuration might bring their structure to certain regularity (crystalline character) even though $T_{\mathrm{m}}$ were not observed clearly as yet.

\section{Biochemical Oxygen Demand Test}

Biochemical oxygen demand (BOD) values of the above mentioned samples in the presence of an activated sludge were measured by a BOD tester for 30 days. The relationship of BOD/TOD values vs. elapse of time can be plotted as Figure 3.

The BOD/TOD values of saturated polyester $\mathbf{P 1}$ were $54.3 \%$ after 30 days, however, these values of unsaturated polyesters P2a-e were region of $5.9(\mathbf{P 2 a})$ to $32.4 \%$ (P2c) after 30 days. Introducing of $\mathrm{C}=\mathrm{C}$ double bonds to aliphatic polyester made more or less the rate of the degradation slow down. Especially polyester P2a having all $Z$-configuration of $\mathrm{C}=\mathrm{C}$ double bonds was found to degrade hardly in the course of the BOD test. However polyester P2b ( $E$-configuration fraction: $34 \%$ ) and P2c ( $E$-configuration fraction: 63\%) became to degrade much faster than polyester P2a. This rate enhancement should be contributed by increasing of $E$ configuration fraction in the $\mathrm{C}=\mathrm{C}$ double bonds. It is now obvious fact that $Z$ - and $E$-configuration in the $\mathrm{C}=\mathrm{C}$ double bonds affected their biodegradability in the different manner, suggesting that the difference in geometrical structure might be recognized by microorganisms in an activated sludge. In other words, the biodegradation rate can be controlled by the introduction of some $\mathrm{C}=\mathrm{C}$ double bond in chain of aliphatic polyester and further adjusted finely depending on its $Z / E$ ratio.

When the E-configuration fraction increased over 
$84 \%$, however, degradation rate of the samples was suppressed against our expectation. There are many articles in which the effect of crystallinity of the sample on its biodegradability was pointed out. ${ }^{17,18}$ Generally speaking, highly crystalline polyester samples tend to inhibit their smooth degradation by microorganisms, regardless of its chemical structure. It was already noted that rising-up of $T_{\mathrm{g}}$ was observed as increasing of the $E$-configuration fraction (Table I). Therefore this reversion in $E$-configuration rich region suggests that the biodegradability of these samples must be controlled by not only preference due to the geometrical structure but also other factors, maybe its crystallinity etc.

\section{CONCLUSION}

Unsaturated and saturated aliphatic polyesters (P2a and P1) were synthesized by ring-opening copolymerization of corresponding anhydrides with PO. The geometrical structure of $\mathrm{C}=\mathrm{C}$ double bonds in polyester P2a was found to be $100 \% Z$-configuration, in contrast with the solution polycondensation of unsaturated acid anhydrides with ethylene glycol using a protonic catalyst. In order to investigate geometrical effects on biodegradability, polyesters P2b-e were derived from one original polymer P2a by isomerization reaction from $Z$ - to $E$-configuration in DCE in the presence of Mor. It is clear that the different geometrical structure of the polymer, $Z$ - and $E$-configuration in the $\mathrm{C}=\mathrm{C}$ double bonds, affected to their biodegradability. Especially polyester P2a having all $Z$-configuration of $\mathrm{C}=\mathrm{C}$ double bonds was found to degrade hardly in the course of the BOD test. The biodegradability of $E$-configuration was found to be superior to $Z$-configuration. In order to discuss biodegradation rate of polyesters strictly, it might be necessary to take into account their crystallinity, too.

\section{REFERENCES}

1. Y. Tokiwa and T. Suzuki, Nature, 270, 76 (1977).

2. N. Valiente, T. Lalot, M. Brigodiot, and E. Marechal, J. Polym. Sci., Part A: Polym. Chem., 35, 27 (1997).

3. N. Valiente, T. Lalot, M. Brigodiot, and E. Marechal, J. Polym. Sci., Part A: Polym. Chem., 35, 35 (1997).

4. H. Jin, D. Kim, B. Lee, M. Kim, I. Lee, H. Lee, and J. Yoon, J. Polym. Sci., Part B: Polym. Phys., 38, 2240 (2000).

5. A. Takasu, M. Ito, Y. Inai, T. Hirabayashi, and Y. Nishimura, Polym. J., 31, 961 (1999).

6. S. Takenouchi, A. Takasu, Y. Inai, and T. Hirabayashi, Polym. J., 33, 746 (2001).

7. W. H. Carothers and J. A. Arivin, J. Am. Chem. Soc., 51, 2560 (1929).

8. T. Akita and S. Oishi, Kogyo Kagaku Zassi, 58, 315 (1935).

9. I. V. Szmeresanyl, K. M. Greger, and E. Makaybodl, J. Polym. Sci., 53, 241, (1961).

10. L. V. Cristobal and P. M. Gilberto A., Polym. Bull., 22, 513 (1989).

11. Y. Maeda, A. Nakayama, J. Iyoda, K. Hayashi, and N. Yamamoto, Kobunshi Ronbunshu, 50, 723 (1993).

12. Y. Maeda, A. Nakayama, N. Kawasaki, K. Hayashi, and N. Yamamoto, Kobunshi Ronbunshu, 51, 771 (1994).

13. Y. Maeda, A. Nakayama, N. Kawasaki, K. Hayashi, and N. Yamamoto, Polymer, 38, 4719 (1997).

14. N. Toyoda, M. Yoshida, and T. Otsu, Polym. J., 15, 255 (1983).

15. Y. Maeda, A. Nakayama, N. Kawasaki, K. Hayashi, S. Aiba, and N. Yamamoto, J. Environ. Polym. Degrad., 4, 225 (1996).

16. Y. Maeda, A. Nakayama, N. Kawasaki, K. Hayashi, S. Aiba, and N. Yamamoto, Polym. J., 29, 836 (1997).

17. M. Mochizuki, K. Mukai, K. Yamada, N. Ichise, S. Murase, and Y. Iwaya, Macromolecules, 30, 7403 (1997).

18. T. Iwata and Y. Doi, Macromol. Chem. Phys., 200, 2429 (1999). 